\title{
Oral Yohimbine as a New Probe Drug to Predict CYP2D6 Activity: Results of a Fixed-Sequence Phase I Trial
}

\author{
Manuela Vay ${ }^{1} \cdot$ Marleen Julia Meyer $^{2} \cdot$ Antje Blank $^{1} \cdot$ Gisela Skopp $^{3} \cdot$ Peter Rose $^{1} \cdot$ Mladen Vassilev Tzvetkov $^{2}$. \\ Gerd Mikus ${ }^{1}$ (D)
}

Published online: 15 February 2020

(c) The Author(s) 2020

\begin{abstract}
Objective Yohimbine pharmacokinetics were determined after oral administration of a single oral dose of yohimbine $5 \mathrm{mg}$ and a microdose of yohimbine $50 \mu \mathrm{g}$ in relation to different cytochrome P450 (CYP) 2D6 genotypes. The CYP2D6 inhibitor paroxetine was used to investigate the influence on yohimbine pharmacokinetics. Microdosed midazolam was applied to evaluate a possible impact of yohimbine on CYP3A activity and the possibility of combining microdosed yohimbine and midazolam to simultaneously determine CYP2D6 and CYP3A activity.

Methods In a fixed-sequence clinical trial, 16 healthy volunteers with a known CYP2D6 genotype [extensive (10), intermediate (2) and poor (4) metaboliser] received an oral dose of yohimbine $50 \mu \mathrm{g}$, yohimbine $5 \mathrm{mg}$ at baseline and during paroxetine as a CYP2D6 inhibitor. Midazolam $(30 \mu \mathrm{g})$ was co-administered to determine CYP3A activity at each occasion. Plasma concentrations of yohimbine, its main metabolite 11-OH-yohimbine, midazolam and paroxetine were quantified using validated liquid chromatography-tandem mass spectrometry assays.

Results Pharmacokinetics of yohimbine were highly variable and a CYP2D6 genotype dependent clearance was observed. After yohimbine $5 \mathrm{mg}$, the clearance ranged from 25.3 to $15,864 \mathrm{~mL} / \mathrm{min}$ and after yohimbine $50 \mu \mathrm{g}$, the clearance ranged from 39.6 to $38,822 \mathrm{~mL} / \mathrm{min}$. A more than fivefold reduction in clearance was caused by paroxetine in CYP2D6 extensive metabolisers, while the clearance in poor metabolisers was not affected. Yohimbine did not alter CYP3A activity as measured by microdosed midazolam.

Conclusions The pharmacokinetics of yohimbine were highly correlated with CYP2D6, which was further supported by the clearance inhibition caused by the CYP2D6 inhibitor paroxetine. With these data, yohimbine is proposed to be a suitable probe drug to predict CYP2D6 activity. In addition, the microdose can be used in combination with microdosed midazolam to simultaneously evaluate CYP2D6 and CYP3A activity without any interaction between the probe drugs and because the microdoses exert no pharmacological effects.
\end{abstract}

Clinical Trial Registration EudraCT2017-001801-34.

Electronic supplementary material The online version of this article (https://doi.org/10.1007/s40262-020-00862-6) contains supplementary material, which is available to authorized users.

Gerd Mikus

gerd.mikus@med.uni-heidelberg.de

1 Department of Clinical Pharmacology and Pharmacoepidemiology, University Hospital Heidelberg, Im Neuenheimer Feld 410, 69120 Heidelberg, Germany

2 Institute of Clinical Pharmacology, University Medical Center Göttingen, Göttingen, Germany

3 Institute of Forensic Medicine, Munich, Germany

\section{Key Points}

This is the first study to demonstrate the major cytochrome P450 2D6 dependency of the clearance of yohimbine.

Yohimbine as a potential probe drug for cytochrome P450 2D6 activity can also be used in a microdose setting to minimise the risk for any potential study population. 


\section{Introduction}

Major variability in drug exposure results from large differences in drug-metabolising enzyme activities. Currently, genotyping and phenotyping tests are used to assess cytochrome P450 (CYP) activity. Although genotyping is a tempting approach propagated widely to define variability $[1,2]$, the influence of environmental factors on CYP450 activity is not captured by genotyping [3]. It is almost impossible to assess all known (rare) genetic variants on a routine basis and a translation into a phenotype may be very difficult or even impossible $[4,5]$. Therefore, the need for specific phenotyping tests is growing, leading to the evaluation of endogenous substances for this purpose [6] to avoid exposure to probe drugs. Microdosing of probe drugs, however, might be an alternative because it poses only a minimal additional risk to the patient. Necessary requirements are high enzyme specificity and sensitivity of the microdosed probe drug. A further advantage of microdosed probe drugs is the ability to combine those microdosed probe drugs without causing drug-drug interactions $[7,8]$.

CYP2D6 is an important drug-metabolising enzyme with approximately $20 \%$ of approved drugs being metabolised by CYP2D6 [9, 10]. However, this enzyme undergoes a genetic polymorphism resulting in highly variable enzyme activity with about $10 \%$ poor metabolisers (PMs), $10-15 \%$ intermediate metabolisers (IMs), $1-2 \%$ ultra-rapid metabolisers and the remaining largest group of extensive metabolisers (EMs) in the Caucasian population $[11,12]$.

Yohimbine is an $\alpha_{2}$-receptor antagonist licensed in Germany (since 1978) as well as Canada (since 1951) [13] for erectile dysfunction but pharmacodynamic effects are not fully understood [14]. In vitro data indicate that CYP2D6 seems likely to catalyse the specific transformation of yohimbine into 11-OH-yohimbine [15]. We therefore evaluated in a clinical study the potential of yohimbine as a phenotyping probe drug using a therapeutic dose as well as a microdose of yohimbine in a CYP2D6 panel study. Moreover, a further objective was to investigate the effect of CYP2D6 inhibition by paroxetine on yohimbine pharmacokinetics after a therapeutic dose and microdose. The combination of microdosed yohimbine with the established microdosed CYP3A probe drug midazolam $[16,17]$ was also studied.

\section{Methods}

The trial protocol was approved by the Ethics Committee of the Medical Faculty of Heidelberg University (Germany) and the competent authority (BfArM, Bonn, Germany) and registered at the European Union Drug Regulating Authorities for Clinical Trials (EudraCT2017-001801-34). The trial was conducted at the clinical trial unit of the Department of Clinical Pharmacology and Pharmacoepidemiology (KliPS, certified according to ISO 9001:2015, Heidelberg University Hospital, Germany) in accordance with International Council for Harmonisation of Technical Requirements for Pharmaceuticals for Human Use Good Clinical Practice guidelines and the current Declaration of Helsinki. All included volunteers gave their written informed consent prior to any study procedures.

\subsection{Study Design}

This open-label, fixed-sequence, clinical phase I trial investigated the pharmacokinetics of yohimbine following single oral administration in healthy volunteers with different CYP2D6 genotypes. Two different doses of yohimbine (50 $\mu \mathrm{g}$ and $5 \mathrm{mg}$ ) were administered to determine the pharmacokinetics and dose proportionality of yohimbine. In addition, the effect of CYP2D6 inhibition by paroxetine on the pharmacokinetics of yohimbine was to be studied. To evaluate a possible influence of yohimbine on CYP3A activity, microdosed midazolam $(30 \mu \mathrm{g})$ was co-administered as a marker substance. A single oral dose of midazolam $30 \mu \mathrm{g}$ was administered before any other treatment to determine baseline CYP3A activity.

The chronological trial procedures are shown in Fig. 1. Microdoses of yohimbine $(50 \mu \mathrm{g})$ and midazolam $(30 \mu \mathrm{g})$ were administered orally. After a washout period of 1 week, a therapeutic yohimbine dose $(5 \mathrm{mg})$ together with midazolam $30 \mu \mathrm{g}$ was administered. The CYP2D6 inhibition part was started after another washout (1 week) using paroxetine $(20 \mathrm{mg}$ ) once daily for 3 days. On the second day, microdosed yohimbine $(50 \mu \mathrm{g})$ was administered immediately after the paroxetine. On the third day, the yohimbine 5 -mg therapeutic dose was administered in the same manner. Midazolam $(30 \mu \mathrm{g})$ was given at the same time as paroxetine on each of the 3 paroxetine days.

To administer the midazolam microdose, an oral solution was freshly prepared $(30 \mu \mathrm{L}$ of a $1-\mathrm{mg} / \mathrm{mL}$ stock solution, Dormicum ${ }^{\circledR} \mathrm{V}$; Roche-Pharma, Grenzach-Wyhlen, Germany, diluted in $100 \mathrm{~mL}$ of tap water in a plastic cup) $30 \mathrm{~min}$ before administration. Yohimbine and paroxetine were administered orally as tablets (Yohimbinum hydrochloricum D $4^{\circledR}$; Deutsche Homöopathie Union, Karlsruhe, Germany, containing $25 \mu \mathrm{g}$ per tablet; Yocon Glenwood ${ }^{\circledR}$ $5 \mathrm{mg}$; Cheplapharm, Greifswald, Germany; Paroxat ${ }^{\circledR} 20 \mathrm{mg}$; Hexal AG, Holzkirchen, Germany). 


\begin{tabular}{|c|c|c|c|c|c|c|c|}
\hline Day 1 & Day 2 & $\begin{array}{c}\text { Washout } \\
1 \text { week }\end{array}$ & Day 9 & $\begin{array}{c}\text { Washout } \\
1 \text { week }\end{array}$ & Day 16 & Day 17 & Day 18 \\
\hline \multirow[t]{4}{*}{ MDZ $30 \mu \mathrm{g}$} & MDZ $30 \mu \mathrm{g}$ & & MDZ $30 \mu \mathrm{g}$ & & MDZ $30 \mu \mathrm{g}$ & MDZ $30 \mu \mathrm{g}$ & MDZ $30 \mu \mathrm{g}$ \\
\hline & YOH $50 \mu \mathrm{g}$ & & & & & YOH $50 \mu \mathrm{g}$ & \\
\hline & & & YOH $5 \mathrm{mg}$ & & & & YOH 5 mg \\
\hline & & & & & PAR $20 \mathrm{mg}$ & PAR $20 \mathrm{mg}$ & PAR $20 \mathrm{mg}$ \\
\hline
\end{tabular}

Fig. 1 Clinical trial design. $M D Z$ midazolam, $P A R$ paroxetine, $Y O H$ yohimbine

\subsection{Study Population}

Potential participants had to pass a thorough physical and mental health evaluation (medical history, physical assessments, vital signs, electrocardiogram and laboratory evaluation, normal renal and liver function tests). Their resting blood pressure had to be $90-140 \mathrm{mmHg}$ systolic and $50-90 \mathrm{mmHg}$ diastolic, heart rate between 50 and 90 beats $/ \mathrm{min}$ and weight $\geq 50 \mathrm{~kg}$. Participants of child-bearing potential were obliged to use a reliable contraceptive method with a Pearl Index $<1 \%$. Regular drug treatment for at least 2 weeks before inclusion was not allowed except for oral contraceptives or any intake of substances that induce or inhibit drug-metabolising enzymes or drug transporters within a period of less than ten times of the respective elimination half-life or 3 weeks (whatever was longer). Volunteers were not included if they participated in a clinical trial within the previous 6 weeks, donated blood within 8 weeks (male participants)/12 weeks (female participants) before inclusion or haemoglobin $\leq 11 \mathrm{~g} / \mathrm{dL}$, any physical disorder that could interfere with a participant's safety during the clinical trial or with the study objectives; any acute or chronic illness, or clinically relevant findings in the pre-study examination, especially; any condition that could modify absorption, distribution, metabolism or excretion of the drug regimen under investigation; (history/suspicion of) abuse/or dependency of drugs or substances, allergies (except for mild forms of hay fever) or hypersensitivity reactions to drugs in history, regular smoking (five or more cigarettes/week), regular intake of alcoholic beverages, poor mental development or difficulties in communication with the investigator, suspected non-adherence, any contraindications against midazolam, yohimbine or paroxetine or a known intolerance of a substance or its additives and for female participants: pregnancy or lactation.

\subsection{Cytochrome P450 (CYP) 2D6 Genotyping}

All participants were genotyped for CYP2D6 using a modification of the single-base primer extension method by Sistonen et al. [18]. The method is described in detail in the Electronic Supplementary Material. CYP2D6 allelic variants were translated into an activity score (AS) [19] for further calculations.

\subsection{Study Conduct}

On the yohimbine pharmacokinetic study days, blood samples $(7.5 \mathrm{~mL})$ were taken from a peripheral venous catheter before and $0.25,0.5,0.75,1,1.25,1.5,1.75,2,2.5,3,4,5$, $6,8,10,12$ and $24 \mathrm{~h}$ after administration into heparinised tubes (S-Monovette ${ }^{\circledR}$; Sarstedt AG, Nümbrecht, Germany), and plasma was separated. To determine CYP3A activity using microdosed midazolam, blood samples were taken before and 2, 2.5, 3 and $4 \mathrm{~h}$ after administration [20]. Blood samples were centrifuged at $4{ }^{\circ} \mathrm{C}$ and $3600 \times g$ and plasma was divided into different aliquots and stored at $-20^{\circ} \mathrm{C}$.

\subsection{Quantification of Yohimbine, Paroxetine and Midazolam}

Plasma midazolam and 1-OH-midazolam concentrations were quantified according to a previously published ultraperformance liquid chromatography-tandem mass spectrometry assay [21]. Lower limits of quantification (LLOQ) were $0.37 \mathrm{pg} / \mathrm{mL}$ for midazolam and $0.26 \mathrm{pg} / \mathrm{mL}$ for $1-\mathrm{OH}$ midazolam. Plasma yohimbine and 11-OH-yohimbine were determined using two methods because two doses with a 100-fold difference were administered. For the microdosed yohimbine, plasma concentrations for the parent drug and its metabolite were determined using an ultra-performance liquid chromatography-tandem mass spectrometry assay with an LLOQ of $5 \mathrm{pg} / \mathrm{mL}$ each [22]. After the 5-mg dose, 
plasma concentrations of yohimbine and 11-OH-yohimbine were quantified by a liquid chromatography-tandem mass spectrometry method with an LLOQ of $0.5 \mathrm{ng} / \mathrm{mL}$ [23]. Plasma paroxetine concentrations were determined by the same assay with an LLOQ of $0.5 \mathrm{ng} / \mathrm{mL}$. All assays are validated according to the US Food and Drug Administration's and European Medicines Agency's pertinent guidelines for bioanalytical method validation requiring accuracy and precision values within $\pm 15 \%[24,25]$.

To determine the plasma protein binding of yohimbine after both the 5- and 50- $\mu$ g doses, a rapid equilibrium dialysis assay (Thermo Fisher Scientific, Rockford, IL, USA) was performed at high concentrations $(200 \mu \mathrm{L}$ of plasma of the 0.5-h sample and $400 \mu \mathrm{L}$ of Dulbecco's phosphate buffered saline as a dialysis buffer for a dialysis time of $4 \mathrm{~h}$ ). Equal volumes of plasma and buffer were processed and analysed in the same manner as the plasma samples [22].

\subsection{Calculations and Statistical Analysis}

Standard non-compartmental pharmacokinetic parameters of yohimbine, 11-OH-yohimbine and paroxetine were calculated using Kinetica 5.0 (Thermo Fisher Scientific, Waltham, MA, USA): maximum plasma concentration $\left(C_{\max }\right)$, time to reach maximum plasma concentration, terminal elimination half-life, area under the plasma concentration-time curve (AUC) extrapolated to infinity, volume of distribution at steady state and apparent oral clearance. A mixed loglinear model was used for AUC calculation. For CYP3A activity evaluation, a limited sampling strategy using AUC from 2 to $4 \mathrm{~h}$ was used to calculate the metabolic clearance as described previously [26]. Pharmacokinetic data are presented as geometric mean and $95 \%$ confidence intervals unless stated otherwise.

To evaluate the effect of different $C Y P 2 D 6$ genotypes on yohimbine pharmacokinetic parameters, an ordinary analysis of variance after logarithmic transformation was used. To study the effect of CYP2D6 inhibition by paroxetine on yohimbine and midazolam pharmacokinetics, a repeatedmeasures analysis of variance after logarithmic transformation was applied. A $p$ value $<0.05$ was considered significant. The statistical analysis was performed using Prism 7.02 (GraphPad Software Inc., La Jolla, CA, USA).

\section{Results}

Sixteen healthy Caucasian women $(n=7)$ and men $(n=9)$ with a known $C Y P 2 D 6$ genotype (EMs, $n=10$; IMs, $n=2$, PMs, $n=4$ ) were included (age 23-59 years, body mass

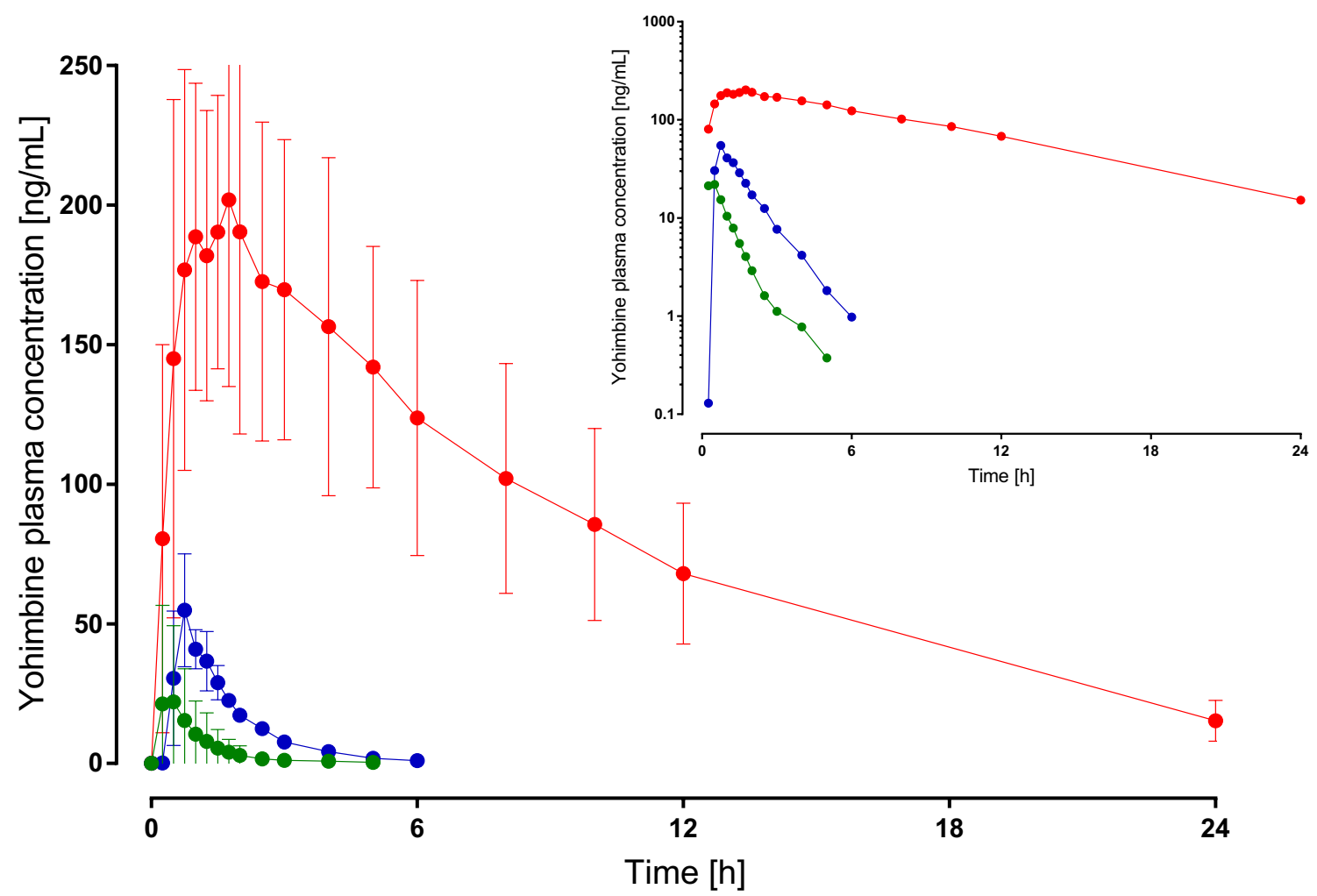

Fig. 2 Yohimbine plasma concentration-time curves divided into genotypes after administration of yohimbine 5 mg in linear and logarithmic presentations. Red points and line: poor metaboliser; blue points and line: intermediate metaboliser, green points and line: extensive metaboliser 
index $18.8-31.2 \mathrm{~kg} / \mathrm{m}^{2}$ ). Two participants discontinued the trial before the paroxetine administration part for personal reasons.

\subsection{Yohimbine Pharmacokinetics After a Single 5-mg Oral Dose}

After oral administration of yohimbine $5 \mathrm{mg}$, highly variable plasma concentrations were observed (Fig. 2). Maximum concentrations were reached quickly in all participants, but there were large significant differences between the CYP2D6 genotypes (Table 1) with $C_{\max }$ more than tenfold higher in
PMs compared with EMs. These genotype-related significant differences were also observed for AUC, volume of distribution at steady state, apparent oral clearance and terminal elimination half-life (Table 1). The high clearance of yohimbine in EMs $(5130 \mathrm{~mL} / \mathrm{min})$ is reduced by a factor more than 100 in PMs where it is a low-clearance drug at $41 \mathrm{~mL} / \mathrm{min}$. Correspondingly, the terminal elimination halflife is more than $6 \mathrm{~h}$ in PMs in contrast to the fast elimination in EMs (less than $1 \mathrm{~h}$ ).

Plasma concentration-time profiles of the metabolite 11-OH-yohimbine were different between the CYP2D6 genotypes mainly during the first $3 \mathrm{~h}$ after yohimbine

Table 1 Pharmacokinetic parameter of yohimbine $5 \mathrm{mg}$ and its metabolite 11-OH-yohimbine after a single oral dose and during treatment with paroxetine $20 \mathrm{mg}$ stratified according to the cytochrome $P 4502 \mathrm{D} 6$ genotype

\begin{tabular}{|c|c|c|c|c|c|c|c|c|}
\hline & \multicolumn{4}{|c|}{ Yohimbine $5 \mathrm{mg}(n=10)$} & \multicolumn{4}{|c|}{+ Paroxetine $20 \mathrm{mg}(n=10)$} \\
\hline & \multicolumn{2}{|l|}{ Yohimbine } & \multicolumn{2}{|c|}{ 11-OH-yohimbine } & \multicolumn{2}{|l|}{ Yohimbine } & \multicolumn{2}{|c|}{ 11-OH-yohimbine } \\
\hline & Geom. mean & $95 \% \mathrm{CI}$ & Geom. mean & $95 \% \mathrm{CI}$ & Geom. mean & $95 \% \mathrm{CI}$ & Geom. mean & $95 \% \mathrm{CI}$ \\
\hline \multicolumn{9}{|l|}{ EM } \\
\hline$C_{\max }(\mathrm{ng} / \mathrm{mL})$ & $17.5^{\mathrm{a}, \mathrm{d}}$ & $9.14-33.3$ & $69.2^{\mathrm{a}}$ & $54.9-87.3$ & $59.5^{\mathrm{d}}$ & $34.6-102$ & $53.2^{\mathrm{a}}$ & $42.2-66.9$ \\
\hline$t_{\max }(\mathrm{h})^{\mathrm{e}}$ & $0.36^{\mathrm{a}, \mathrm{b}}$ & $0.28-0.49$ & $0.42^{\mathrm{a}}$ & $0.33-0.56$ & 0.42 & $0.31-0.65$ & $0.40^{\mathrm{a}}$ & $0.28-0.68$ \\
\hline $\mathrm{AUC}(\mathrm{ng} / \mathrm{mL} * \mathrm{~h})$ & $16.2^{\mathrm{a}, \mathrm{b}, \mathrm{d}}$ & $8.93-29.5$ & 480 & $418-550$ & $109^{\mathrm{a}, \mathrm{d}}$ & $48.7-24.2$ & 551 & $470-645$ \\
\hline$t_{1 / 2}(\mathrm{~h})$ & $0.64^{\mathrm{a}, \mathrm{d}}$ & $0.55-0.74$ & $13.25^{\mathrm{a}}$ & $11.8-14.9$ & $1.24^{\mathrm{a}, \mathrm{d}}$ & $0.91-1.70$ & 15.5 & $13.8-17.5$ \\
\hline$V_{\mathrm{ss}} / F(\mathrm{~L})$ & $313^{\mathrm{a}, \mathrm{d}}$ & $166-589$ & & & $18.3^{\mathrm{d}}$ & $9.40-35.6$ & & \\
\hline $\mathrm{Cl} / F(\mathrm{~mL} / \mathrm{min})$ & $5130^{\mathrm{a}, \mathrm{b}, \mathrm{w}}$ & $2821-9330$ & & & $768^{\mathrm{a}, \mathrm{d}}$ & $344-1711$ & & \\
\hline MR AUC & $0.03^{\mathrm{a}, \mathrm{b}, \mathrm{d}}$ & $0.02-0.06$ & & & $0.20^{\mathrm{a}, \mathrm{d}}$ & $0.10-0.40$ & & \\
\hline IM & $(n=2)$ & & & & $(n=2)$ & & & \\
\hline$C_{\max }(\mathrm{ng} / \mathrm{mL})$ & 52.9 & $1.76-1592$ & $37.4^{\mathrm{c}}$ & $15.1-92.6$ & 107 & $5.66-2035$ & 24.6 & $0.005-112,113$ \\
\hline$t_{\max }(\mathrm{h})^{\mathrm{e}}$ & $0.75^{\mathrm{b}}$ & & $0.75^{\mathrm{c}}$ & & 0.71 & & 1.05 & \\
\hline $\operatorname{AUC}\left(\mathrm{ng} / \mathrm{mL}^{*} \mathrm{~h}\right)$ & $78.7^{\mathrm{b}, \mathrm{c}}$ & $16.5-375$ & 376 & 78.8-1795 & 488 & $37.6-6325$ & 436 & 201-947 \\
\hline$t_{1 / 2}(\mathrm{~h})$ & $0.96^{\mathrm{c}, \mathrm{d}}$ & $0.05-18.5$ & 14.8 & $4.6-48.2$ & $2.86^{\mathrm{d}}$ & $0.05-172$ & 14.86 & $0.008-2550$ \\
\hline$V_{\mathrm{ss}} / F(\mathrm{~L})$ & 115 & $3.34-3946$ & & & 59.6 & $2.45-1448$ & & \\
\hline $\mathrm{Cl} / F(\mathrm{~mL} / \mathrm{min})$ & $1059^{b, c}$ & $222-5047$ & & & 171 & $13.2-2218$ & & \\
\hline MR AUC & $0.21^{\mathrm{b}, \mathrm{c}}$ & $0.21-0.21$ & & & 1.12 & $0.04-31.5$ & & \\
\hline PM & $(n=4)$ & & & & $(n=2)$ & & & \\
\hline$C_{\max }(\mathrm{ng} / \mathrm{mL})$ & $198^{\mathrm{a}}$ & $121-327$ & $12.0^{\mathrm{a}, \mathrm{c}}$ & $4.56-31.6$ & 151 & $12.2-1864$ & $12.7^{\mathrm{a}}$ & $0.33-485$ \\
\hline$t_{\max }(\mathrm{h})^{\mathrm{e}}$ & 1.42 & $0.97-2.64$ & $6.67^{\mathrm{a}, \mathrm{c}}$ & $4.93-10.3$ & 1.54 & & $5.46^{\mathrm{a}}$ & \\
\hline AUC (ng/mL*h) & $2044^{\mathrm{a}, \mathrm{c}}$ & $1073-3895$ & 584 & $135-2528$ & $1410^{\mathrm{a}}$ & $409-4861$ & 427 & $290-628$ \\
\hline$t_{1 / 2}(\mathrm{~h})$ & $6.59^{\mathrm{a}, \mathrm{c}}$ & $5.20-8.35$ & $31.2^{\mathrm{a}}$ & $11.5-84.7$ & $5.95^{\mathrm{a}}$ & $2.78-12.7$ & 21.16 & $0.72-619$ \\
\hline$V_{\mathrm{ss}} / F(\mathrm{~L})$ & $24.5^{\mathrm{a}}$ & $14.8-40.7$ & & & 203 & $124-334$ & & \\
\hline $\mathrm{Cl} / F(\mathrm{~mL} / \mathrm{min})$ & $40.8^{\mathrm{a}, \mathrm{c}}$ & $21.4-77.7$ & & & $59.1^{\mathrm{a}}$ & $17.41-204$ & & \\
\hline MR AUC & $3.50^{\mathrm{a}, \mathrm{c}}$ & $0.63-19.5$ & & & $3.3^{\mathrm{a}}$ & $1.42-7.75$ & & \\
\hline
\end{tabular}

$A U C$ area under the plasma concentration-time curve, $C I$ confidence interval, $C l / F$ apparent oral clearance, $C_{\text {max }}$ maximum plasma concentration, EM extensive metaboliser, Geom. mean geometric mean, IM intermediate metaboliser, MR AUC metabolic AUC ratio (AUC yohimbine/ AUC 11-OH-yohimbine), $P M$ poor metaboliser, $s t_{\max }$ time to reach maximum plasma concentration, $t_{1 / 2}$ terminal elimination half-life, $V_{s s} / F$ volume of distribution at steady state; $p<0.05$

${ }^{a} \mathrm{EM}$ vs PM

${ }^{b} \mathrm{EM}$ vs IM

${ }^{\mathrm{c}} \mathrm{PM}$ vs IM

${ }^{\mathrm{d}}$ Without vs with paroxetine (repeated measures)

${ }^{\mathrm{e}}$ Harmonic mean 


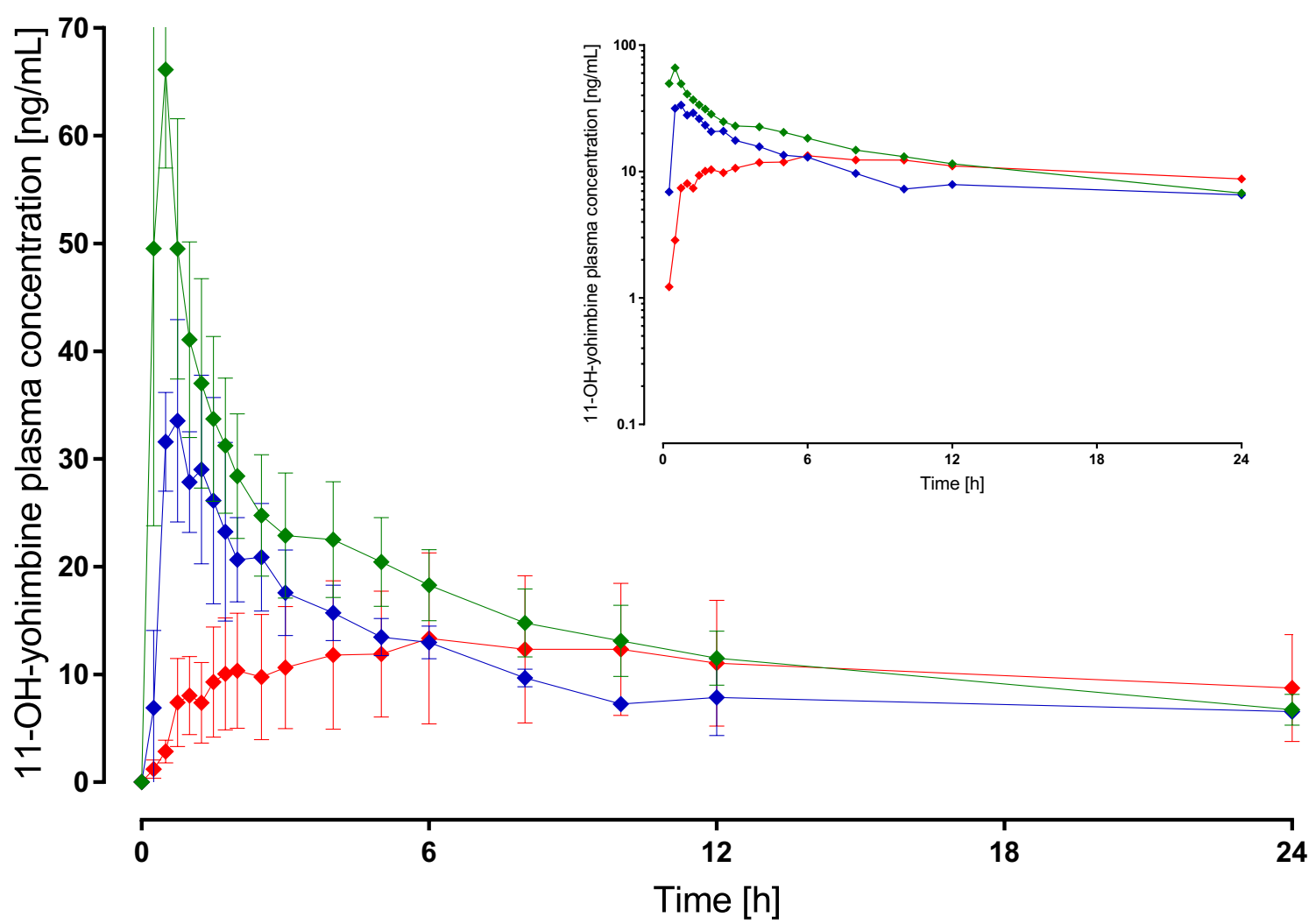

Fig. 3 11-OH-yohimbine plasma concentration-time curves divided into genotypes after administration of yohimbine $5 \mathrm{mg}$ in linear and logarithmic presentations. Red diamond and line: poor metaboliser;

administration (Fig. 3). This is reflected in fivefold lower $C_{\max }$ values in PMs and also in a later time to reach maximum plasma concentration, which was prolonged to almost $7 \mathrm{~h}$ in PMs (Table 1). Elimination of 11-OH-yohimbine is much longer than for its parent drug (Table 1). The fraction unbound was determined for yohimbine at $2.8 \pm 0.9 \%$ and for $11-\mathrm{OH}$-yohimbine at $6.3 \pm 4.0 \%$.

\subsection{Yohimbine Pharmacokinetics After a Single 50-rg Oral Dose}

Using an oral microdose of $50 \mu \mathrm{g}$, the pharmacokinetics of yohimbine was highly variable and similar to the pharmacokinetics after a 5-mg dose in relation to the CYP2D6 genotypes. Clearly, a differentiation between the three CYP2D6 genotypes can be observed for the yohimbine (Fig. 4) and 11-OH-yohimbine (Fig. 5) plasma concentration-time profiles as well as the resulting pharmacokinetic parameters $C_{\max }$, AUC, terminal elimination half-life, volume of distribution at steady state and apparent oral clearance (Table 2). The high clearance of yohimbine in EMs $(11,152 \mathrm{~mL} / \mathrm{min})$ is reduced by a factor more than 200 in PMs where it is a low-clearance drug at $55 \mathrm{~mL} / \mathrm{min}$. blue diamonds and line: intermediate metaboliser; green diamonds and line: extensive metaboliser

Differences in the 11-OH-yohimbine plasma concentration-time profiles between the CYP2D6 genotypes were limited to the first hours after administration (Fig. 5). Maximum concentrations were reached after $0.5 \mathrm{~h}$ in EMs, after $1 \mathrm{~h}$ in IMs and only after more than $7 \mathrm{~h}$ in PMs, while maximum concentrations were a fifth in PMs and half in IMs compared with EMs. Terminal elimination half-life was doubled in PMs compared with EMs but AUCs were almost similar for all three groups of genotypes (Table 2). The fraction unbound was determined for yohimbine at $1.9 \pm 2.1 \%$ and for $11-\mathrm{OH}$-yohimbine at $5.5 \pm 2.8 \%$.

\subsection{Influence of Paroxetine on Yohimbine Pharmacokinetics}

In EMs, the CYP2D6 inhibitor paroxetine significantly increased $C_{\max }$, AUC and elimination half-life of yohimbine and reduced volume of distribution and clearance (Fig. 6) irrespective of the yohimbine dose used (Tables 1,2). In addition, the metabolite 11-OH-yohimbine showed increased exposure (AUC and $C_{\max }$ ) during paroxetine (Table 2).

In contrast, no statistically significant alteration of yohimbine pharmacokinetics was observed in PMs using both 5-mg and 50- $\mu \mathrm{g}$ yohimbine doses. No effect on 11-OH-yohimbine 


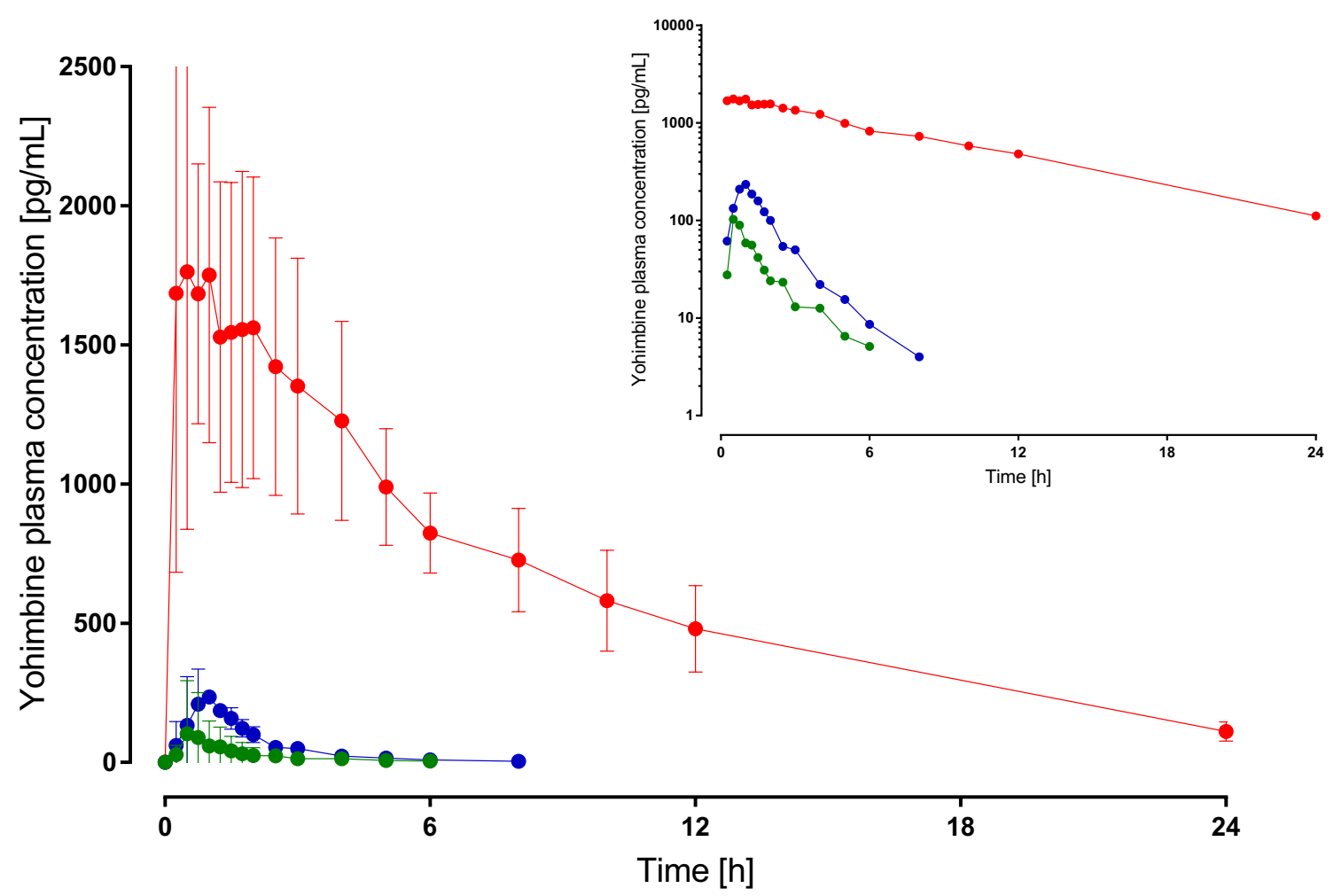

Fig. 4 Yohimbine plasma concentration-time curves divided into genotypes after administration of yohimbine $50 \mu \mathrm{g}$ in linear and logarithmic presentations. Red points and line: poor metaboliser; blue points and line: intermediate metaboliser; green points and line: extensive metaboliser

pharmacokinetic parameters was observed after the 5-mg

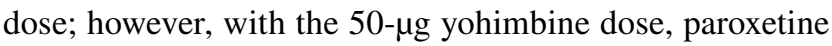
increased AUC and $C_{\max }$ significantly (Table 2).

In the two IMs, paroxetine did not alter yohimbine pharmacokinetics irrespective of the yohimbine dose used (Tables 1,2), except a prolongation of the yohimbine terminal elimination half-life was observed after yohimbine $5 \mathrm{mg}$. No changes in 11-OH-yohimbine pharmacokinetics by paroxetine were seen.

\subsection{CYP3A Activity}

Using the limited sampling methodology after single administration of an oral microdose of midazolam $30 \mu \mathrm{g}$, the AUC from 2 to $4 \mathrm{~h}$ was $371 \pm 235 \mathrm{pg} / \mathrm{mL}^{*} \mathrm{~h}(n=16)$. No statistically significant changes were observed during yohimbine, paroxetine and yohimbine plus paroxetine treatments irrespective of the yohimbine dose (Table 3). Correspondingly, no significant alterations of the calculated metabolic clearance of midazolam were observed (Table 3).

\subsection{Safety}

In total, 13 adverse events occurred in 9 of 16 participants. The most frequent events observed were headache $(n=3)$ and nausea $(n=3)$, in one case with vomiting. All events were temporary. Most ( 8 out of 13) events occurred during the paroxetine treatment period.

\section{Discussion}

\subsection{Yohimbine and CYP2D6}

After administration of an oral therapeutic dose of yohimbine $(5 \mathrm{mg})$ as well as a microdose $(50 \mu \mathrm{g})$, highly variable pharmacokinetics of yohimbine and its main metabolite in plasma 11-OH-yohimbine were observed. The apparent oral clearance of yohimbine in this healthy volunteer population varied more than 600 -fold from 25.3 to $15,864 \mathrm{~mL} / \mathrm{min}$ after the single oral 5-mg dose and even more than 900 -fold from 39.6 to $38,822 \mathrm{~mL} / \mathrm{min}$ after the single oral $50-\mu \mathrm{g}$ dose. This variability is clearly associated with the polymorphic CYP2D6 enzyme because yohimbine clearance was highest in CYP2D6 EMs and lowest in PMs. Calculating the fractional clearance of yohimbine via CYP2D6 by $1-\left(\mathrm{AUC}_{\mathrm{EM}} /\right.$ $\left.\mathrm{AUC}_{\mathrm{PM}}\right)$ using the mean values of both genotype groups after the 50- $\mu$ g administration results in 0.995 , which demonstrates the almost exclusive and complete elimination of yohimbine via the CYP2D6-mediated 11-hydroxylation. In 


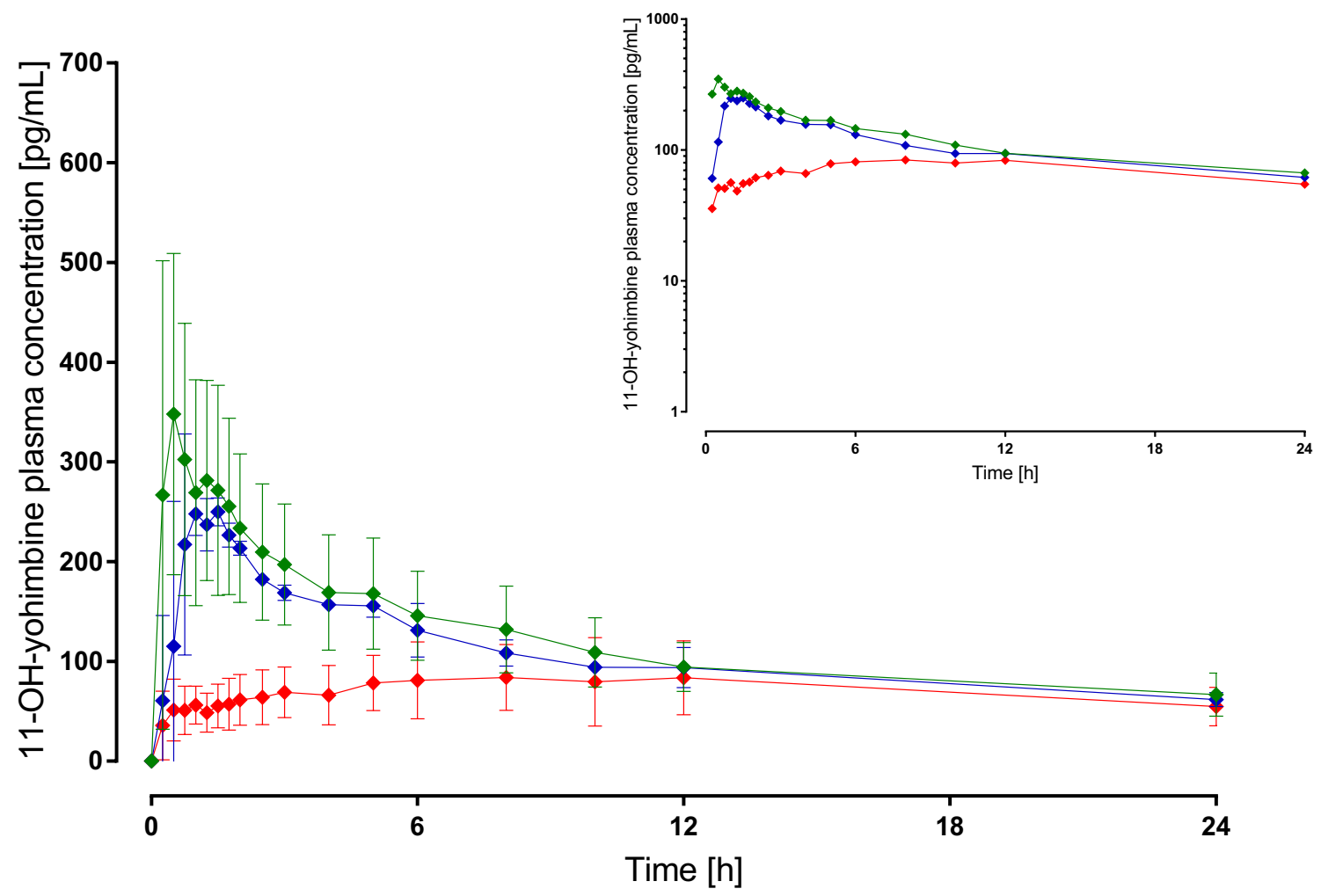

Fig. 5 11-OH-yohimbine plasma concentration-time curves divided into genotypes after administration of yohimbine $50 \mu \mathrm{g}$ in linear and logarithmic presentations. Red diamonds and line: poor metaboliser;

a pharmacokinetic study using oral and intravenous yohimbine, 1 out of 12 healthy study participants showed a 15 -fold reduced yohimbine clearance [27]. This slow metaboliser was said to co-segregate with the CYP2D6 polymorphism.

Considerable variability of yohimbine pharmacokinetics was reported in an earlier study with healthy volunteers [28]. There, one of eight volunteers showed a 10- to 20 -fold lower yohimbine clearance. A bioavailability study in seven healthy volunteers demonstrated a range from less than $10 \%$ up to $90 \%$ bioavailability, and the one volunteer with the lowest clearance and highest bioavailability was at least discussed [29]. Another study investigated the yohimbine pharmacokinetics after intravenous bolus administration in 13 healthy volunteers. Again, one volunteer showed a tenfold lower metabolic clearance than the rest of the group [30]. Overall, this occurrence of reduced metabolism in about $10 \%$ of the study participants fits well with the knowledge that in a Caucasian population, the frequency of $C Y P 2 D 6$ PMs ranges between 7 and $10 \%$ [12].

A larger study involving 172 volunteers to investigate the $\alpha_{2}$-adrenegic blockade demonstrated that after a 15-min yohimbine infusion no concentration of the metabolite 11-OH-yohimbine was measurable at this time point in 17 volunteers [15]. The study identified ten PMs by genotyping; blue diamonds and line: intermediate metaboliser; green diamonds and line: extensive metaboliser

however, a conclusive analysis was not performed probably owing to the single metabolite concentration measured at $15 \mathrm{~min}$ (end of infusion). However, in vitro enzyme kinetics showed CYP2D6 is responsible for the 11-OH-yohimbine formation [15]. With the results of our CYP2D6 panel study, it becomes evident that CYP2D6 plays the major role in yohimbine elimination via 11-hydroxylation with extreme differences in yohimbine clearance between the CYP2D6 genotypes.

The role of CYP2D6 in yohimbine elimination is further supported by the paroxetine interaction results. Paroxetine is a very potent serotonin reuptake inhibitor and also a substrate and an inhibitor of CYP2D6 [31]. Paroxetine significantly decreased yohimbine clearance in EM and IM subjects, but not in PMs. This was observed when using the $5-\mathrm{mg}$ and 50- $\mu \mathrm{g}$ yohimbine doses. It has been shown that paroxetine is able to change the CYP2D6 phenotype measured by dextromethorphan as a probe drug [32]. Subjects with one functional allele converted to the PM phenotype by $94 \%$ whereas $56 \%$ of subjects with two functional alleles changed their phenotype to PM during paroxetine treatment [32].

If a drug is eliminated predominantly by a certain enzyme (i.e. CYP3A or CYP2D6), the clearance to the 
Table 2 Pharmacokinetic parameter of yohimbine $50 \mu \mathrm{g}$ and its metabolite 11-OH-yohimbine after a single oral dose and during treatment with paroxetine $20 \mathrm{mg}$ stratified according to the cytochrome P450 2D6 genotype

\begin{tabular}{|c|c|c|c|c|c|c|c|c|}
\hline & \multicolumn{4}{|c|}{ Yohimbine $50 \mu \mathrm{g}(n=10)$} & \multicolumn{4}{|c|}{+ Paroxetine $20 \mathrm{mg}(n=10)$} \\
\hline & \multicolumn{2}{|l|}{ Yohimbine } & \multicolumn{2}{|c|}{ 11-OH-yohimbine } & \multicolumn{2}{|l|}{ Yohimbine } & \multicolumn{2}{|c|}{ 11-OH-yohimbine } \\
\hline & Geom. mean & $95 \% \mathrm{CI}$ & Geom. mean & $95 \% \mathrm{CI}$ & Geom. mean & $95 \% \mathrm{CI}$ & Geom. mean & $95 \% \mathrm{CI}$ \\
\hline \multicolumn{9}{|l|}{ EM } \\
\hline$C_{\max }(\mathrm{pg} / \mathrm{mL})$ & $73.9^{\mathrm{a}, \mathrm{b}, \mathrm{d}}$ & $35.4-154$ & $446^{\mathrm{a}, \mathrm{d}}$ & $342-581$ & $249^{\mathrm{d}}$ & $129-481$ & $848^{\mathrm{a}, \mathrm{d}}$ & $732-983$ \\
\hline$t_{\max }(\mathrm{h})^{\mathrm{e}}$ & $0.36^{\mathrm{a}}$ & $0.28-0.49$ & 0.43 & $0.31-0.70$ & 0.42 & $0.31-0.65$ & 0.42 & $0.31-0.69$ \\
\hline $\mathrm{AUC}\left(\mathrm{pg} / \mathrm{mL}^{*} \mathrm{~h}\right)$ & $74.7^{\mathrm{a}, \mathrm{b}, \mathrm{d}}$ & $36.1-155$ & $4374^{\mathrm{d}}$ & $3621-5283$ & $290^{\mathrm{a}, \mathrm{b}, \mathrm{d}}$ & $176-479$ & $15,649^{d}$ & $9106-26,894$ \\
\hline$t_{1 / 2}(\mathrm{~h})$ & $0.68^{\mathrm{a}, \mathrm{b}, \mathrm{d}}$ & $0.58-0.80$ & $16.0^{\mathrm{a}}$ & $13.42-19.2$ & $1.29^{\mathrm{a}, \mathrm{d}}$ & $0.98-1.70$ & 20.22 & $13.8-29.6$ \\
\hline$V_{\mathrm{ss}} / F(\mathrm{~L})$ & $810^{\mathrm{a}, \mathrm{b}, \mathrm{d}}$ & $421-1558$ & & & $231^{\mathrm{a}, \mathrm{d}}$ & $124-430$ & & \\
\hline $\mathrm{Cl} / F(\mathrm{~mL} / \mathrm{min})$ & $11,152^{\mathrm{a}, \mathrm{b}, \mathrm{d}}$ & $5381-23,115$ & & & $2066^{\mathrm{a}, \mathrm{d}}$ & $869-4911$ & & \\
\hline MR AUC & $0.02^{\mathrm{a}, \mathrm{b}}$ & $0.01-0.05$ & & & $0.04^{\mathrm{a}}$ & $0.02-0.06$ & & \\
\hline $\mathrm{IM}$ & $(n=2)$ & & & & $(n=2)$ & & & \\
\hline$C_{\max }(\mathrm{pg} / \mathrm{mL})$ & $266^{\mathrm{b}, \mathrm{c}}$ & 58.8-1197 & $277^{c}$ & $123-628$ & 815 & $126-5253$ & 566 & $223-1439$ \\
\hline$t_{\max }(\mathrm{h})^{+}$ & $0.75^{\mathrm{c}}$ & & 1.0 & & 0.71 & & 0.60 & \\
\hline $\mathrm{AUC}\left(\mathrm{pg} / \mathrm{mL}^{*} \mathrm{~h}\right)$ & $456^{\mathrm{b}, \mathrm{c}}$ & $374-556$ & 4216 & $2064-8614$ & $2588^{\mathrm{b}}$ & $113-59,583$ & $14,066^{\mathrm{c}}$ & $48.4-4,089,742$ \\
\hline$t_{1 / 2}(\mathrm{~h})$ & $1.33^{\mathrm{b}, \mathrm{c}}$ & $0.94-1.90$ & 19.1 & $6.62-54.9$ & 2.50 & $0.04-164.8$ & 24.0 & $0.24-2363$ \\
\hline$V_{\mathrm{ss}} / F(\mathrm{~L})$ & $226^{\mathrm{b}, \mathrm{c}}$ & $18.8-2730$ & & & 83.0 & $54.0-128$ & & \\
\hline $\mathrm{Cl} / F(\mathrm{~mL} / \mathrm{min})$ & $1829^{\mathrm{b}, \mathrm{c}}$ & $1500-2231$ & & & 322 & $14.0-7411$ & & \\
\hline MR AUC & $0.10^{\mathrm{a}}$ & $0.05-0.19$ & & & 0.24 & $0.19-0.30$ & & \\
\hline PM & $(n=4)$ & & & & $(n=2)$ & & & \\
\hline$C_{\max }(\mathrm{pg} / \mathrm{mL})$ & $2188^{\mathrm{a}, \mathrm{c}}$ & $965-4963$ & $83.8^{\mathrm{a}, \mathrm{c}, \mathrm{d}}$ & $42.0-167.2$ & 1392 & $563-3444$ & $395^{\mathrm{a}, \mathrm{d}}$ & $37.2-4195$ \\
\hline$t_{\max }(\mathrm{h})^{\mathrm{e}}$ & $1.42^{\mathrm{a}, \mathrm{c}}$ & $0.97-2.64$ & $7.27^{\mathrm{a}, \mathrm{c}}$ & $4.44-20.1$ & 1.54 & & $8.00^{\mathrm{a}, \mathrm{c}}$ & \\
\hline $\operatorname{AUC}\left(\mathrm{ng} / \mathrm{mL}^{*} \mathrm{~h}\right)$ & $15,274^{\mathrm{a}, \mathrm{c}}$ & $9427-24,745$ & $4402^{\mathrm{d}}$ & $2165-8948$ & $12,229^{a}$ & $4946-30,237$ & $20,276^{d}$ & $1.88-2,191,230$ \\
\hline$t_{1 / 2}(\mathrm{~h})$ & $5.85^{\mathrm{a}, \mathrm{c}}$ & $5.57-6.14$ & $34.71^{\mathrm{a}}$ & $13.0-92.7$ & $5.55^{\mathrm{a}}$ & $2.53-12.2$ & 33.7 & $0.04-30,114$ \\
\hline$V_{\mathrm{ss}} / F(\mathrm{~L})$ & $28.4^{\mathrm{a}, \mathrm{c}}$ & $16.7-48.4$ & & & $36.9^{\mathrm{a}}$ & $11.8-116$ & & \\
\hline $\mathrm{Cl} / F(\mathrm{~mL} / \mathrm{min})$ & $54.6^{\mathrm{a}, \mathrm{c}}$ & $33.7-88.4$ & & & $68.1^{\mathrm{a}}$ & $27.6-169$ & & \\
\hline MR AUC & $3.53^{\mathrm{a}, \mathrm{c}}$ & $2.11-5.90$ & & & $3.66^{\mathrm{a}}$ & $0.61-21.84$ & & \\
\hline
\end{tabular}

$A U C$ area under the plasma concentration-time curve, $C I$ confidence interval, $C l / F$ apparent oral clearance, $C_{\text {max }}$ maximum plasma concentration, IM intermediate metaboliser, EM extensive metaboliser, Geom. mean geometric mean, MR AUC metabolic AUC ratio (AUC yohimbine/ AUC 11-OH-yohimbine), $P M$ poor metaboliser, $t_{\max }$ time to reach maximum plasma concentration, $t_{1 / 2}$ terminal elimination half-life, $V_{s s} / F$ volume of distribution at steady state, $p<0.05$

${ }^{a} \mathrm{EM}$ vs PM

${ }^{b}$ EM vs IM

${ }^{c} \mathrm{PM}$ vs IM

${ }^{\mathrm{d}}$ Without vs with paroxetine (repeated measures)

${ }^{\mathrm{e}}$ Harmonic mean

drug (i.e. midazolam or yohimbine) reflects the enzyme activity responsible for the elimination. These drugs with predominant and specific pathways are probe drugs and can be used for phenotyping of metabolic enzyme or transporter activity. This process is established for midazolam as a probe drug for CYP3A [33, 34]. For enzymes with genetic polymorphisms such as CYP2D6, it has been proposed to replace phenotyping by genotyping and a CYP2D6 AS has been established that should reflect the enzyme activity [35]. When transforming the alleles of the study participants into the CYP2D6 AS, this resulted in AS $0(n=4)$, AS $0.5(n=2)$, AS $1(n=2)$ and AS 2 $(n=8)$. The yohimbine clearance was evaluated for a relationship with this AS, which is shown in Fig. 7 for the $50-\mu \mathrm{g}$ yohimbine dose. There is a significant log-linear relationship with a weighted $r^{2}$ of 0.56 , which may be due to the limited data points or a wrong model. However, the clearances of the AS groups deviate largely from the predicted clearance. At AS 0 , a clearance of $250 \mathrm{~mL} / \mathrm{min}$ is predicted by the model, which indicates a 4.6 -fold overestimation as the average measured clearance was $55 \mathrm{~mL} /$ min. Furthermore, at AS 1, the predicted clearance is 2.1fold underestimated (Fig. 7). At AS 2, the almost twofold overestimated yohimbine clearance increases to 10.6-fold 
Fig. 6 Comparison of yohimbine clearance after oral administration of yohimbine $5 \mathrm{mg}$ and yohimbine $50 \mu \mathrm{g}$ alone and during paroxetine
Table 3 Geometric mean (95\% confidence interval) and area under the curve of samples from 2 to $4 \mathrm{~h}\left(\mathrm{AUC}_{2-4}\right)$ and metabolic clearance $\left(\mathrm{Cl}_{\text {met }}\right)$ after midazolam $30 \mu \mathrm{g}$ under different co-medications
$50 \mu g$

$5 \mathrm{mg}$

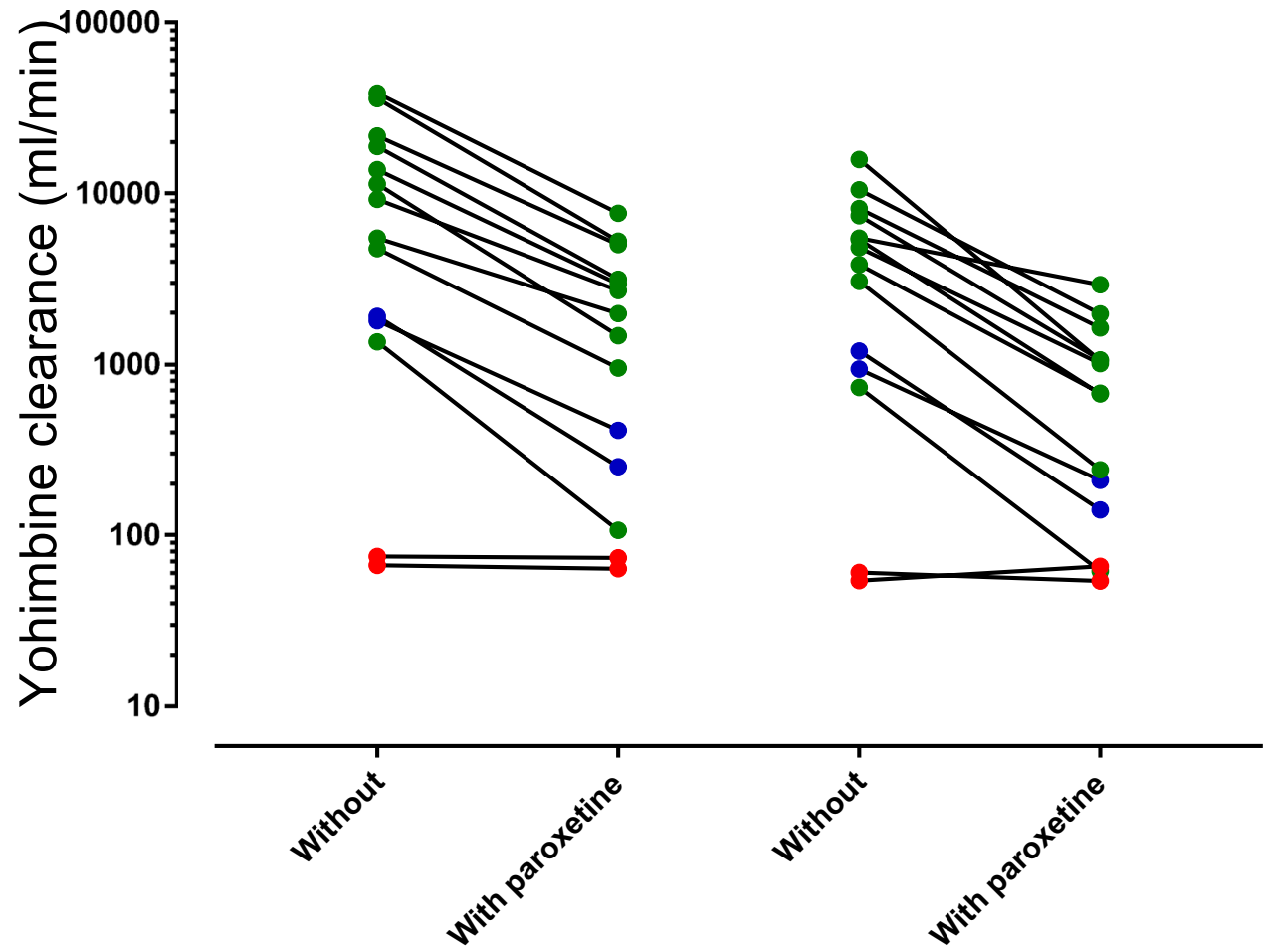

\begin{tabular}{lllll}
\hline $\begin{array}{l}\text { Midazolam } \\
\text { dose }\end{array}$ & Yohimbine dose & Paroxetine dose & $\mathrm{AUC}_{2-4}(\mathrm{pg} / \mathrm{mL} * \mathrm{~h})$ & $\mathrm{Cl}_{\text {met }}(\mathrm{mL} / \mathrm{min})$ \\
\hline $30 \mu \mathrm{g}$ & - & & $371(227-606)$ & $545(414-717)$ \\
$30 \mu \mathrm{g}$ & $50 \mu \mathrm{g}$ & & $259(147-456)$ & $584(459-744)$ \\
$30 \mu \mathrm{g}$ & $5 \mathrm{mg}$ & & $351(217-568)$ & $575(457-722)$ \\
$30 \mu \mathrm{g}$ & & $20 \mathrm{mg}$ & $286(176-464)$ & $613(476-790)$ \\
$30 \mu \mathrm{g}$ & $50 \mu \mathrm{g}$ & $20 \mathrm{mg}$ & $340(200-577)$ & $607(474-779)$ \\
$30 \mu \mathrm{g}$ & $5 \mathrm{mg}$ & $20 \mathrm{mg}$ & $317(180-559)$ & $652(516-824)$ \\
\hline
\end{tabular}

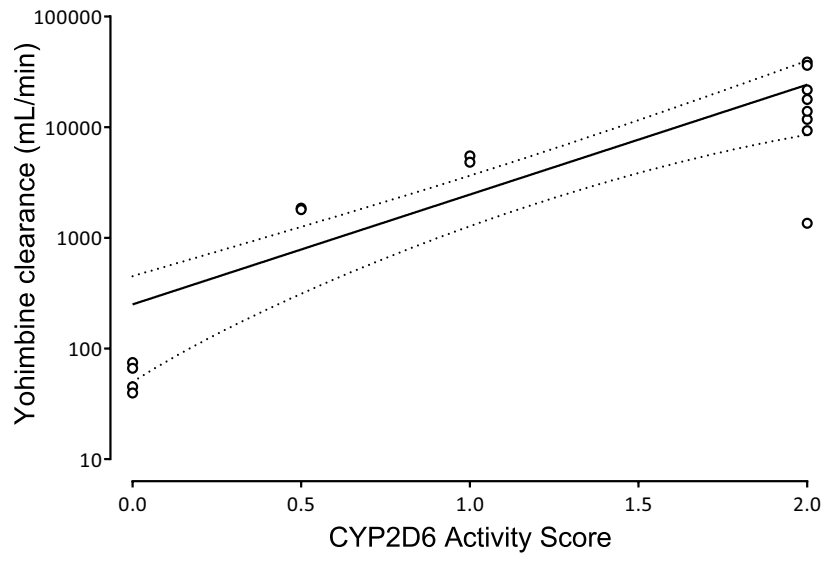

Fig. 7 Relationship between yohimbine clearance and cytochrome P450 2D6 (CYP2D6) activity score after single oral administration of yohimbine $50 \mu \mathrm{g}$ during paroxetine treatment, which is the result of potent CYP2D6 inhibition.

The major drawbacks of genotyping are large inter-individual variabilities within genotype groups or AS groups that can be observed in this study for AS 2 . These variabilities occur regardless of the phenotyping method employed and also the contribution of phenoconversion resulting from non-genetic extrinsic factors modifying enzyme activity but not the genotype [35-37].

\subsection{CYP2D6 Phenotyping}

For certain probe drugs used for phenotyping of certain enzymes, the metabolic ratio between the parent drug and the metabolite of interest or vice versa is often applied as an activity measure [38-40]. The metabolic ratio of 
yohimbine/11-OH-yohimbine AUCs can also be used for determination of enzyme activity. Interestingly, the pharmacokinetics of the yohimbine metabolite 11-OH-yohimbine showed a CYP2D6 genotype dependency only during the first hours after yohimbine administration, which is during the metabolite formation period given the short half-life of yohimbine. The elimination of 11-OH-yohimbine seems to be independent of CYP2D6 as the terminal elimination halflife is very similar in all genotypes.

CYP2D6 phenotyping had a number of probe drugs over the last decades with sparteine and debrisoquine widely used [41, 42]. However, both probe drugs are no longer available and dextromethorphan was selected as a suitable probe drug [43]. Typically, the urinary metabolic ratio of dextromethorphan and dextrorphan is used as an activity measure [34]. A long elimination half-life restricts the use of dextromethorphan especially in drug-drug interaction trials. Furthermore, CYP3A is involved in the metabolism of dextrorphan, the metabolite formed via CYP2D6 [44]. The microdose approaches using dextromethorphan have been dismissed because of non-linear pharmacokinetics $[45,46]$. Therefore, microdosed yohimbine might be a valid future option to phenotype accurately CYP2D6 activity in humans. Of course, a validation study must be conducted and these data should also be compared to the current standard phenotyping method using dextromethorphan.

With this study, we also suggest including microdosed yohimbine for microdosed cocktails used to assess enzyme activities. Both the 5-mg and 50- $\mu$ g yohimbine doses did not alter the estimated partial metabolic clearance of midazolam using a $30-\mu \mathrm{g}$ oral midazolam dose simultaneously. However, the advantages of the microdoses are that there are no expected pharmacodynamic effects and thus drug-related side effects in trials are reduced to a minimum. Midazolam and yohimbine appear suitable for a simultaneous microdose administration to identify possible drug-drug interactions or perpetrator properties of new drugs.

\subsection{Protein Binding}

The plasma protein binding of yohimbine and 11-OHyohimbine was determined to be substantially higher than previously observed (yohimbine: $97.2 \%$ vs $82 \%$; $11-\mathrm{OH}-$ yohimbine: $93.7 \%$ vs $43 \%$ ) [47]. There are methodological differences in the method of determination (ultrafiltration vs rapid equilibrium dialysis) with rapid equilibrium dialysis currently the most commonly used and established approach [48].

\subsection{Limitations}

Certainly, the small number of participants in the PM and IM groups is a limitation of this investigation. However, because results of the genotype groups for yohimbine exposure, clearance and half-life were large and clearly separated, the conclusions of this trial are justified. Indeed, the main interest was the ability to determine the activity of CYP2D6, which was achieved. In addition, CYP2D6 inhibition resulted in the expected decrease of yohimbine clearance in EM and IM participants whereas insignificant changes in PMs were expected because of a lack of functional enzymes and/or alternative pathways. Unfortunately, no ultra-rapid metaboliser could be identified during the genotype screening. The highest observed clearance of yohimbine $50 \mu \mathrm{g}$ was $38.8 \mathrm{~L} / \mathrm{min}$, which might even be much higher in ultra-rapid metabolisers, which would then result in a more than 1000fold difference in yohimbine clearance in the population.

\section{Conclusions}

A therapeutic dose $(5 \mathrm{mg})$ and microdose $(50 \mu \mathrm{g})$ of yohimbine were successfully applied to evaluate the CYP2D6 activity in $C Y P 2 D 6$ genotyped healthy persons. CYP2D6 inhibition significantly decreased yohimbine clearance. Microdosed yohimbine can also be combined with microdosed midazolam to simultaneously determine CYP2D6 and CYP3A activity. Microdosed yohimbine seems to be exclusively eliminated by CYP2D6 and is therefore an excellent candidate to become a reference probe drug for CYP2D6 activity assessment.

Acknowledgements Open Access funding provided by Projekt DEAL. The authors thank Kathrin Foerster for monitoring the study, Annika Elbe, Brit-Silja Rohr, Vanessa Zhu, Florian Michel and Marlies StützleSchnetz for their excellent assistance during the study performance, and Jürgen Burhenne, Magdalena Longo and Andrea Deschlmayr for their support in the development of the method and analyses of the samples.

\section{Compliance with Ethical Standards}

Funding This trial was funded by internal resources of the Department of Clinical Pharmacology and Pharmacoepidemiology, University Hospital Heidelberg. No medical writing support was used.

Conflict of interest Manuela Vay, Marleen Julia Meyer, Antje Blank, Gisela Skopp, Peter Rose, Mladen Vassilev Tzvetkov and Gerd Mikus have no conflicts of interest that are directly relevant to the content of this article.

Ethics approval All procedures performed in studies involving human participants were in accordance with International Council for Harmonisation of Technical Requirements for Pharmaceuticals for Human Use Good Clinical Practice guidelines and the ethical standards of the current Declaration of Helsinki.

Consent to participate All included volunteers gave their written informed consent prior to any study procedures.

Trial registration The trial was registered at the European Union Drug Regulating Authorities for Clinical Trials (EudraCT2017-001801-34). 
Open Access This article is licensed under a Creative Commons Attribution-NonCommercial 4.0 International License, which permits any non-commercial use, sharing, adaptation, distribution and reproduction in any medium or format, as long as you give appropriate credit to the original author(s) and the source, provide a link to the Creative Commons licence, and indicate if changes were made. The images or other third party material in this article are included in the article's Creative Commons licence, unless indicated otherwise in a credit line to the material. If material is not included in the article's Creative Commons licence and your intended use is not permitted by statutory regulation or exceeds the permitted use, you will need to obtain permission directly from the copyright holder.To view a copy of this licence, visit http://creativecommons.org/licenses/by-nc/4.0/.

\section{References}

1. Ingelman-Sundberg M, Sim SC, Gomez A, Rodriguez-Antona C. Influence of cytochrome $\mathrm{P} 450$ polymorphisms on drug therapies: pharmacogenetic, pharmacoepigenetic and clinical aspects. Pharmacol Ther. 2007;116(3):496-526.

2. Zanger UM, Schwab M. Cytochrome P450 enzymes in drug metabolism: regulation of gene expression, enzyme activities, and impact of genetic variation. Pharmacol Ther. 2013;138(1):103-41.

3. McGraw J, Gerhardt A, Morris TC. Opportunities and obstacles in genotypic prediction of cytochrome P450 phenotypes. Expert Opin Drug Metab Toxicol. 2018;14(7):659-61.

4. Shah RR, Gaedigk A, Llerena A, Eichelbaum M, Stingl J, Smith RL. CYP450 genotype and pharmacogenetic association studies: a critical appraisal. Pharmacogenomics. 2016;17(3):259-75.

5. Hicks JK, Swen JJ, Gaedigk A. Challenges in CYP2D6 phenotype assignment from genotype data: a critical assessment and call for standardization. Curr Drug Metab. 2014;15(2):218-32.

6. Magliocco G, Thomas A, Desmeules J, Daali Y. Phenotyping of human CYP450 enzymes by endobiotics: current knowledge and methodological approaches. Clin Pharmacokinet. 2019;58(11):1373-91.

7. Mikus G. Probes and cocktails for drug-drug interaction evaluation: the future is microdosing? Clin Pharmacol Ther. 2019;105(6):1335-7.

8. Mikus G, Foerster KI, Schaumaeker M, Lehmann ML, Burhenne J, Haefeli WE. Microdosed cocktail of three oral factor Xa inhibitors to evaluate drug-drug interactions with potential perpetrator drugs. Clin Pharmacokinet. 2019;58(9):1155-63.

9. Ingelman-Sundberg M. Genetic polymorphisms of cytochrome P450 2D6 (CYP2D6): clinical consequences, evolutionary aspects and functional diversity. Pharmacogenom J. 2005;5(1):6-13.

10. Zhou SF, Liu JP, Chowbay B. Polymorphism of human cytochrome P450 enzymes and its clinical impact. Drug Metab Rev. 2009;41(2):89-295.

11. Zhou SF. Polymorphism of human cytochrome P450 2D6 and its clinical significance: part I. Clin Pharmacokinet. 2009;48(11):689-723

12. Zanger UM, Raimundo S, Eichelbaum M. Cytochrome P450 2D6: overview and update on pharmacology, genetics, biochemistry. Naunyn Schmiedebergs Arch Pharmacol. 2004;369(1):23-37.

13. Wishart DS, Feunang YD, Guo AC, Lo EJ, Marcu A, Grant JR, et al. DrugBank 5.0: a major update to the DrugBank database for 2018. Nucleic Acids Res. 2018;46(D1):D1074-82.

14. Tam SW, Worcel M, Wyllie M. Yohimbine: a clinical review. Pharmacol Ther. 2001;91(3):215-43.

15. Le Corre P, Parmer RJ, Kailasam MT, Kennedy BP, Skaar TP, $\mathrm{Ho} \mathrm{H}$, et al. Human sympathetic activation by alpha2-adrenergic blockade with yohimbine: bimodal, epistatic influence of cytochrome P450-mediated drug metabolism. Clin Pharmacol Ther. 2004;76(2):139-53.

16. Hohmann N, Haefeli WE, Mikus G. Use of microdose phenotyping to individualise dosing of patients. Clin Pharmacokinet. 2015;54(9):893-900.

17. Hohmann N, Kocheise F, Carls A, Burhenne J, Haefeli WE, Mikus G. Midazolam microdose to determine systemic and pre-systemic metabolic CYP3A activity in humans. Br J Clin Pharmacol. 2015;79(2):278-85.

18. Sistonen J, Fuselli S, Levo A, Sajantila A. CYP2D6 genotyping by a multiplex primer extension reaction. Clin Chem. 2005;51(7):1291-5.

19. Gaedigk A, Simon SD, Pearce RE, Bradford LD, Kennedy MJ, Leeder JS. The CYP2D6 activity score: translating genotype information into a qualitative measure of phenotype. Clin Pharmacol Ther. 2008;83(2):234-42.

20. Katzenmaier S, Markert C, Riedel KD, Burhenne J, Haefeli WE, Mikus G. Determining the time course of CYP3A inhibition by potent reversible and irreversible CYP3A inhibitors using A limited sampling strategy. Clin Pharmacol Ther. 2011;90(5):666-73.

21. Burhenne J, Halama B, Maurer M, Riedel KD, Hohmann N, Mikus G, et al. Quantification of femtomolar concentrations of the CYP3A substrate midazolam and its main metabolite 1'-hydroxymidazolam in human plasma using ultra performance liquid chromatography coupled to tandem mass spectrometry. Anal Bioanal Chem. 2012;402(7):2439-50.

22. Vay M, Sauter M, Mikus G, Burhenne J. Quantification of microdosed oral yohimbine and its major metabolite in human plasma in the picogram range. Bioanalysis. 2019;11(16):1459-67.

23. Vay MSG, Mikus G, Burhenne J. Simultaneous quantification of the CYP2D6 substrate yohimbine, its metabolite 11-OH-yohimbine, and the CYP2D6 inhibitor paroxetine in human plasma. Anal Methods. 2019;11:5976-83 (submitted).

24. US FDA. Guidance for industry: bioanalytical method validation. 2018. https://www.fda.gov/files/drugs/published/Bioanalyti cal-Method-Validation-Guidance-for-Industry.pdf. Accessed 14 Jan 2020.

25. EMA. Bioanalytical method validation. 2011. https://www.ema. europa.eu/en/documents/scientific-guideline/guideline-bioanalyti cal-method-validation_en.pdf. Accessed 14 Jan 2020.

26. Hohmann N, Kreuter R, Blank A, Weiss J, Burhenne J, Haefeli WE, et al. Autoinhibitory properties of the parent but not of the $\mathrm{N}$-oxide metabolite contribute to infusion rate-dependent voriconazole pharmacokinetics. Br J Clin Pharmacol. 2017;83(9):1954-65.

27. Le Corre P, Dollo G, Chevanne F, Le Verge R. Biopharmaceutics and metabolism of yohimbine in humans. Eur J Pharm Sci. 1999;9(1):79-84.

28. Owen JA, Nakatsu SL, Fenemore J, Condra M, Surridge DH, Morales A. The pharmacokinetics of yohimbine in man. Eur J Clin Pharmacol. 1987;32(6):577-82.

29. Guthrie SK, Hariharan M, Grunhaus LJ. Yohimbine bioavailability in humans. Eur J Clin Pharmacol. 1990;39(4):409-11.

30. Hedner T, Edgar B, Edvinsson L, Hedner J, Persson B, Pettersson A. Yohimbine pharmacokinetics and interaction with the sympathetic nervous system in normal volunteers. Eur J Clin Pharmacol. 1992;43(6):651-6.

31. Bourin M, Chue P, Guillon Y. Paroxetine: a review. CNS Drug Rev. 2001;7(1):25-47.

32. Storelli F, Matthey A, Lenglet S, Thomas A, Desmeules J, Daali Y. Impact of CYP2D6 functional allelic variations on phenoconversion and drug-drug interactions. Clin Pharmacol Ther. 2018;104(1):148-57. 
33. Hohmann N, Haefeli WE, Mikus G. CYP3A activity: towards dose adaptation to the individual. Expert Opin Drug Metab Toxicol. 2016;12(5):479-97.

34. Streetman DS, Bertino JS Jr, Nafziger AN. Phenotyping of drug-metabolizing enzymes in adults: a review of in vivo cytochrome $\mathrm{P} 450$ phenotyping probes. Pharmacogenetics. 2000;10(3):187-216.

35. Gaedigk A, Dinh JC, Jeong H, Prasad B, Leeder JS. Ten years' experience with the CYP2D6 activity score: a perspective on future investigations to improve clinical predictions for precision therapeutics. J Pers Med. 2018;8(2):15. https://doi.org/10.3390/ jpm8020015.

36. Shah RR, Smith RL. Addressing phenoconversion: the Achilles' heel of personalized medicine. Br J Clin Pharmacol. 2015;79(2):222-40.

37. Bertilsson L, Dahl ML, Dalen P, Al-Shurbaji A. Molecular genetics of CYP2D6: clinical relevance with focus on psychotropic drugs. Br J Clin Pharmacol. 2002;53(2):111-22.

38. van Dyk M, Miners JO, Marshall JC, Wood LS, Hopkins A, Sorich MJ, et al. Identification of the caffeine to trimethyluric acid ratio as a dietary biomarker to characterise variability in cytochrome P450 3A activity. Eur J Clin Pharmacol. 2019;75(9):1211-8.

39. Tian DD, Natesan S, White JR, Paine MF. Effects of common CYP1A2 genotypes and other key factors on intraindividual variation in the caffeine metabolic ratio: an exploratory analysis. Clin Transl Sci. 2019;12(1):39-46.

40. Jones DR, Gorski JC, Haehner BD, O'Mara EM Jr, Hall SD. Determination of cytochrome P450 3A4/5 activity in vivo with dextromethorphan N-demethylation. Clin Pharmacol Ther. 1996;60(4):374-84.
41. Eichelbaum M, Kroemer HK, Fromm MF. Impact of P450 genetic polymorphism on the first-pass extraction of cardiovascular and neuroactive drugs. Adv Drug Deliv Rev. 1997;27(2-3):171-99.

42. Sloan TP, Lancaster R, Shah RR, Idle JR, Smith RL. Genetically determined oxidation capacity and the disposition of debrisoquine. Br J Clin Pharmacol. 1983;15(4):443-50.

43. Frank D, Jaehde U, Fuhr U. Evaluation of probe drugs and pharmacokinetic metrics for CYP2D6 phenotyping. Eur J Clin Pharmacol. 2007;63(4):321-33.

44. Capon DA, Bochner F, Kerry N, Mikus G, Danz C, Somogyi AA. The influence of CYP2D6 polymorphism and quinidine on the disposition and antitussive effect of dextromethorphan in humans. Clin Pharmacol Ther. 1996;60(3):295-307.

45. Ieiri I, Fukae M, Maeda K, Ando Y, Kimura M, Hirota T, et al. Pharmacogenomic/pharmacokinetic assessment of a four-probe cocktail for CYPs and OATPs following oral microdosing. Int $\mathbf{J}$ Clin Pharmacol Ther. 2012;50(10):689-700.

46. Streetman DS, Ellis RE, Nafziger AN, Leeder JS, Gaedigk A, Gotschall R, et al. Dose dependency of dextromethorphan for cytochrome P450 2D6 (CYP2D6) phenotyping. Clin Pharmacol Ther. 1999;66(5):535-41.

47. Yocon-Glenwood ${ }^{\circledR}$ (yohimbine hydrochloride). Summary of Product Characteristics (Fachinformation), Cheplapharm Arzneimittel GmbH. 2017. Available online to registered medical practitioners from Rote Liste Service GmbH, Frankfurt, Germany. https://www. rote-liste.de/. Accessed 10 Jan 2020.

48. Buscher B, Laakso S, Mascher H, Pusecker K, Doig M, Dillen $\mathrm{L}$, et al. Bioanalysis for plasma protein binding studies in drug discovery and drug development: views and recommendations of the European Bioanalysis Forum. Bioanalysis. 2014;6(5):673-82. 